\title{
OS "ERRES” PÓS PANDEMIA: PRINCÍPIOS PARA SUSTENTABILIDADE E CIDADANIA
}

\author{
Lia Maris Orth Ritter Antiqueira ${ }^{1}$ \\ Elizabete Satsuki Sekine ${ }^{2}$
}

Resumo: Enquanto a ciência busca por uma vacina para a COVID-19 e o controle da pandemia, é preciso pensar em ações de curto, médio e longo prazo que se iniciam hoje, com o olhar voltado para o futuro. Ações de ordem prática que envolvem o ensino remoto temporário e a posterior segurança do contato social nas escolas, a diminuição da produção de resíduos, a reorganização da economia, dentre outras questões que acabam por se organizar como princípios de sustentabilidade e cidadania. É imperativo que todos os setores da sociedade se mobilizem e tomem iniciativas em prol de um futuro comum.

Palavras-chave: COVID-19; Educação Ambiental; Sars-CoV-2; Sustentabilidade.

Abstract: While science is looking for a vaccine for COVID-19 and pandemic control it is necessary to think about short, medium and long-term actions that should start today with a look into the future. Actions involving temporary remote education and the subsequent security of social contact in schools, the decrease in waste production, the reorganization of the economy, as well as other questions that arise as the principles of sustainability and citizenship. It is imperative that all sectors of society mobilize and take initiatives for a common future.

Keywords: COVID-19; Environmental Education; Sars-CoV-2; Sustainability.

1 Universidade Tecnológica Federal do Paraná, Câmpus Ponta Grossa. E-mail: liaantiqueira@utfpr.edu.br. Link para o Lattes: http://lattes.cnpq.br/6914975623530073

2 Universidade Tecnológica Federal do Paraná, Câmpus Ponta Grossa. E-mail: essekine@utfpr.edu.br. Link para o Lattes: http://lattes.cnpq.br/8079819523414548 


\section{Introdução}

O surto de Coronavírus (SARS-CoV-2), causador da COVID-19, teve início na China e a doença se espalhou rapidamente pelo mundo, com diferentes impactos. No dia 11 de março de 2020, a Organização Mundial da Saúde declarou a condição de pandemia, ou seja: a transmissão está espalhada pelos continentes, de forma sustentada ou comunitária, não sendo possível identificar a origem da infecção dos indivíduos (OPAS, 2020).

O mundo não estava preparado para uma crise desta proporção. Não existiam planos estratégicos prontos para serem aplicados a uma pandemia de Coronavírus, ou seja: tudo é novo (FREITAS; NAPIMOGA; DONALISO, 2020).

Há diversas frentes de trabalho envolvidas buscando auxiliar em uma situação tão inusitada e trágica. Enquanto especialistas buscam desenvolver uma vacina e tratamentos eficientes, governos buscam soluções para as consequências econômicas e sociais, instituições e organizações subsidiam o enfrentamento da pandemia com projetos de solidariedade $e$ de desenvolvimento de tecnologias.

Especificamente no Brasil, as universidades públicas vêm dando exemplo de engajamento no enfrentamento da COVID-19. São centenas de projetos que buscam desenvolver tecnologias para os serviços de saúde e atendimento, como a produção de respiradores a baixo custo, produção de produtos de higiene (para uso da população em geral e nos hospitais), confecção de máscaras (para distribuição à diversas instituições de atendimento e população de maior vulnerabilidade) materiais didáticos e pedagógicos, para uso dos professores em atividades remotas de ensino e distribuição gratuita para a população.

Ao mesmo tempo, pesquisadores de diversas áreas realizam estudos, incluindo predições relacionadas ao pico de contaminação, recomendações sobre $o$ isolamento social, grau de confiabilidade e segurança de equipamentos (de proteção individual e hospitalares), dentre tantas contribuições científicas nos diversos campos.

Nesta esfera de atuação, há necessidade de se incluir os educadores ambientais, com papel essencial em pensar como será o "pós-pandemia". É urgente e necessário implementar noções de sustentabilidade voltadas à saúde (das espécies e do planeta), construídas com a mudança de comportamentos variando de pequena à grande escala, nos diversos segmentos da sociedade.

É preciso lembrar que a sustentabilidade traz consigo a noção do que é possível ser mantido, sustentado, cuidado. Envolve a manutenção dos processos, dos recursos e dos seres envolvidos. Esta discussão precisa ser inserida no contexto geral da sociedade e deve suscitar a reflexão, provocando novas ordens de organização individual e coletiva que se iniciem hoje e se tornem permanentes. 


\section{Os princípios da Sustentabilidade no Pós Pandemia}

A Agenda 21 brasileira (BRASIL, 2000) trouxe consigo o conceito de "3 ERRES da Sustentabilidade": Reduzir, Reutilizar e Reciclar. Estes princípios foram se popularizando nos últimos vinte anos a ponto de se tornarem praticamente obrigatórios em todos os programas de Educação Ambiental.

Analisando a situação atual e as possíveis perspectivas de futuro para a espécie humana, há uma necessidade urgente de que os 3 ERRES sejam mais que recomendações e se tornem princípios para um mundo pós-pandemia, incluindo na lista outros ERRES que são cruciais para a humanidade.

A primeira ação que deve ser considerada por todos os povos do mundo após o controle da pandemia, mas que deve ser iniciada desde agora, é REPENSAR o convívio social em todos os aspectos, mas com cuidados redobrados nos ambientes de grande fluxo de pessoas ao longo de horas seguidas.

Tomem-se por exemplo as escolas, que para Nesti e Goldbaum (2007) se configuram como espaço de grande contato social, onde crianças e adolescentes se expõem a fatores de risco infecciosos. Nestes locais, segundo Ferreira et al (2006) a dispersão de microrganismos é facilitada devido à proximidade entre os alunos em sala de aula, principalmente em ambientes fechados, como também potencializados pelo comportamento de risco em relação ao autocuidado e a exposição ambiental.

Sabe-se que as escolas públicas do Brasil possuem salas superlotadas e sem ventilação adequada. É preciso pensar em ambientes que atendam às necessidades de distanciamento entre os alunos e protocolos de higiene na entrada e saída das aulas.

Também é necessário pensar em minimizar possibilidades de contaminação indireta (tosse, espirros, perdigotos) e direta (compartilhamento de copos, talheres, utensílios de higiene) que são apontadas como responsáveis por grande parte das infecções respiratórias desenvolvidas por crianças e jovens em idade escolar. Souza et al. (2015) recomendam extrema atenção aos cuidados com as mãos, na forma de condutas protetoras estimuladas. Protocolos nas entradas dos ambientes com disponibilidade de pias com água corrente e sabonete, toalhas descartáveis, podem ajudar a diminuir os riscos de contaminação.

Os novos protocolos de convívio estimulados pela pandemia devem promover a constante discussão acerca da responsabilidade para consigo e com os outros, de forma a buscar a conscientização para evitar o contágio e a transmissão desta e de outras doenças virais, mostrando que a saúde de cada um depende diretamente das atitudes ou das omissões de todos.

Junto com este "ERRE', vem outro urgente e necessário, que trata de REORGANIZAR o próprio ensino. Afinal, uma das primeiras medidas de enfrentamento ao COVID-19, adotadas em instituições de ensino de grande 
parte do mundo, foi o cancelamento de aulas presenciais em todas as modalidades, com a substituição por atividades remotas ou ensino à distância. Da noite para o dia, professores foram alçados à condição de tutores on-line, muitos sem dominar minimamente as tecnologias de informação e comunicação. Louváveis tentativas de secretarias municipais e estaduais de educação colocaram conteúdos disponíveis pela TV e Internet, assim como universidades chamaram à responsabilidade seus conselhos superiores para propor alternativas a todos os milhões de estudantes a fim de buscar propiciar padrões satisfatórios de ensino na modalidade remota ou à distância.

As mudanças no modo de ensinar fizeram emergir uma ferida social que se tornou latente, ao se perceber uma desigualdade implícita na educação, mostrando a grande quantidade de alunos sem a mínima condição de participar das atividades escolares, seja pela falta do dispositivo tecnológico em si, do acesso à internet, como pela carência de um ambiente calmo e tranquilo para estudar, de uma alimentação de qualidade em casa que o permita ter energia para desenvolver as atividades, do acompanhamento de um professor para esclarecer dúvidas e para motivar seus estudos.

Por outro lado, a mesma ferida mostrou a importância dos professores, das escolas, das bibliotecas, dos cursinhos pré-vestibular gratuitos, do atendimento presencial e individualizado aos alunos, nas chamadas horas atividade, nas salas de recursos especiais e nas monitorias em laboratórios. Estas rotinas por vezes ficam esquecidas e desvalorizadas em meio às demandas do dia a dia, e fizeram surgir uma questão que deve nortear o trabalho pedagógico no Brasil (e porque não no mundo) a partir de agora, que é a garantia que o estudo seja para todos, em iguais condições.

Outra situação que precisa ser analisada com muito critério se refere ao uso de equipamentos de proteção individual (EPIs). É preciso aprender a REUTILIZAR. Estudos comprovaram que a eficácia de máscaras descartáveis e de tecido é praticamente a mesma (FOSCHINI; MONTE, 2020), desde que confeccionadas com as recomendações do Ministério da Saúde (BRASIL, 2020). As máscaras de tecido são laváveis em água e sabão e duradouras, de forma que seu uso diminui consideravelmente a produção de lixo oriundo de máscaras descartáveis, sejam cirúrgicas ou de TNT (tecido não tecido). Até mesmo o elástico das máscaras descartáveis pode ser reaproveitado após desinfecção, sendo reutilizado na confecção de máscaras de tecido.

Além de reutilizar, há que se REDUZIR o consumismo relacionado a estes acessórios, pois tem se tornado moda com diferentes opções de cores, formatos e modelos. Um produto que é confeccionado por cerca de 90 centavos de real, pode chegar a custar mais de cem vezes seu valor se vier com a etiqueta de uma marca conhecida no mercado nacional ou internacional.

Estudos motivados pela pandemia mostram de forma clara algo que já era de conhecimento geral: o modo de vida atual afeta diretamente a saúde do planeta. A redução de emissão de poluentes atmosféricos foi comprovada em 
diversos países devido ao declínio de atividades como transporte e indústria decorrentes da política de isolamento social. Tanto os governos quanto os indivíduos podem aprender a reduzir a poluição a longo prazo (MUHAMMAD; LONG; SALMAN, 2020).

Em um mundo dominado pela lógica capitalista, a transição para a sustentabilidade exige mudanças profundas nos modos de produção e consumo, e o investimento em pesquisas em diversas áreas, desenvolvendo e possibilitando a utilização de tecnologias sustentáveis (LOORBACH; FRANTZESKAKI; AVELIN, 2017; VENTURA et al., 2020).

A sociedade contemporânea tem como características as relações pautadas no consumo, onde se sobressaem o individualismo, a desvalorização do passado e a supervalorização do presente. $O$ foco excessivo no presente prejudica a possibilidade de se pensar no futuro de forma clara (ZUPELARI; WICK, 2015; RATTO, 2017). A mudança de consciência não será fácil e nem rápida, mas é um processo gradual, e o início de toda mudança significativa reside na educação.

Apesar de não ser a única ação necessária à mudança, a educação ambiental é fundamental para resolver os problemas futuros. Os problemas ambientais atuais são parte do sistema civilizatório moderno, uma vez que o sistema econômico se baseia na exploração do ambiente (GOERGEN, 2014). Será preciso uma mudança de consciência que leve ao uso de tecnologias possíveis, mas que hoje ainda não são implantadas devido às políticas contrárias e ao monopólio de grandes corporações.

Ainda com relação às máscaras, elas têm contribuído como fonte de renda para diversas pessoas, instituições e grupos que passaram a realizar a confecção e o comércio artesanal destas, visto que houve queda considerável na economia mundial. São situações paliativas, mas levam à reflexão de que é preciso REPARAR a economia, a fim de diminuir o desemprego e a fome. Para grandes redes de supermercados e cadeias de lanchonetes as perdas, embora consideráveis, não representam a mesma condição crítica que os pequenos proprietários de estabelecimentos, os feirantes, os grupos de economia solidária. É preciso valorizar o comércio local e as pequenas iniciativas de produção agroecológica.

Nessa esfera se inserem também as conexões do ser humano com seu contexto local e com o meio ambiente, no sentido de se REORGANIZAR. Percebeu-se que pequenas ações do cotidiano levaram a uma maior qualidade na saúde mental. As pessoas estão descobrindo o prazer de cuidar de uma pequena horta doméstica, de cultivar os vegetais utilizados em sua alimentação ou de retirar um ramo fresco de erva para fazer seu próprio chá antes de dormir.

Souza e Andrade (2014) relatam que o país antes da pandemia, passava por mudanças na política de saúde, de forma a direcionar a reorganização da atenção básica que resgata os sujeitos sociais, a dinâmica de 
interesses, as relações de cidadania e direito, através de uma ação social que atenda às necessidades da população nos territórios onde vivem. Tal perspectiva envolve ações no ambiente com ênfase na promoção da saúde para proteção à vida. Estas situações precisam ser retomadas com força total. Além disso, as questões do meio ambiente precisam ser incorporadas nas políticas de saúde, bem como a integração das questões de Saúde Ambiental.

Ao discutir a relação necessária entre saúde e meio ambiente, Minayo (2007) aponta que é preciso ilustrar a relação que há entre parasitohospedeiro-ambiente no caso de doenças infectocontagiosas e dar a devida importância aos problemas ambientais em áreas de vulnerabilidade, na forma de uma discussão interdisciplinar.

Quanto a RECICLAR, nunca foi tão necessário. O acúmulo de lixo no planeta vem se tornando caótico. Os recursos naturais se esgotam cada vez mais. É imperativo continuar pensando em fontes de reciclagem de resíduos, principalmente as que permitem a geração de energia. Os aterros sanitários não podem mais ser admitidos.

Segundo Ramos et al. (2011), os resíduos sólidos advindos da saúde compõem parte importante do total dos resíduos sólidos urbanos, não somente pela quantidade gerada, mas pelo potencial risco que afeta a saúde ambiental e coletiva. Porém, dada a elevada demanda atual nos hospitais e demais serviços de atendimento à pacientes contaminados, a produção desta categoria de resíduos teve seus números consideravelmente elevados.

Há inúmeros casos de denúncia de tratamento inadequado, reaproveitamento ou destinação incorreta de resíduos hospitalares de diversos tipos. Uma busca rápida em jornais permite identificar situações consideradas gravíssimas. Para Silva e Hoppe (2005, p. 146), o lixo hospitalar é fonte potencial de propagação de doenças, apresentando risco adicional aos trabalhadores dos serviços de saúde e a comunidade em geral quando tratados de forma inadequada. Garcia e Zanetti-Ramos (2004) endossam esta preocupação, incluindo a questão da preservação ambiental.

Se em 2010 o Instituto Brasileiro de Geografia e Estatística já indicava a produção de 4.000 (quatro mil) toneladas de resíduos produzidos por serviços de saúde a cada dia no país (IBGE, 2010), em 2020 em meio a uma pandemia, este número com certeza é muito maior. Muller et al. (2013) reforçam que os resíduos gerados pela assistência à saúde, quando gerenciados de forma inadequada, são contaminantes potenciais do solo, da água e do ar. É preciso tratamento específico para a preservação do meio ambiente.

Ao se assumir estes princípios de sustentabilidade, torna-se imperativo RECUSAR a visão simplória de que as coisas podem voltar a ser exatamente como eram. É importante voltar a ter normalidade, mas não da forma como antes. Os velhos hábitos são insustentáveis e esta é a oportunidade de realizar uma mudança definitiva. 
Em um cenário em que o país vem perdendo espaço no que se refere à implantação dos Objetivos de Desenvolvimento sustentável da agenda 2030 (VENTURA et al., 2020) será um grande desafio lidar com a educação para a sustentabilidade. Para além dos governos, a mudança deverá estar dentro de cada um, sendo preciso, para manter os ideais acesos, RECOMEÇAR inúmeras vezes, sem perder a esperança, porque a esperança nutre 0 educador ambiental, e a educação ambiental tem e terá um papel crucial na construção de novas maneiras de nos relacionarmos com a sociedade e 0 planeta.

Há que se tomar cuidado, no entanto, com a forma como as questões ambientais são e serão abordadas. Uma preocupação que vem ganhando espaço nas discussões entre educadores ambientais é a utilização da estratégia do medo, em que se mostra um futuro catastrófico, com a natureza se voltando contra o ser humano, ou o discurso da culpa, que impõe ao ser humano o fardo de todos os problemas do mundo.

Discursos de periculosidade e a política do medo, utilizando mensagens apocalípticas podem ter o efeito contrário, intensificando uma atitude individualista em que um culpa o outro ou procura a própria salvação, o que enfraquece as atitudes coletivas. Ao contrário, o que deve emergir desta visão do ambiente em destruição é uma ética de cuidado planetário (RATTO; HENNING; ANDREOLA, 2017). Mesmo que a responsabilidade pela exploração ambiental seja historicamente da espécie humana e do modo de produção predatório, o medo pode ser prejudicial, principalmente quando o trabalho é realizado com crianças, pois pode gerar a sensação de impotência e estimular a desistência.

Antes de colocar o ser humano "fora" ou "contra" a natureza, é preciso RECONECTAR o indivíduo ao ambiente, entendendo o ser humano não como parasita ou destruidor da natureza, mas como parte desta. E antes de estimular a individualidade é preciso REORIENTAR a sociedade de forma coletiva para que o trabalho seja conjunto, envolvendo redes de parcerias, organizações sociais e políticas públicas. Com o trabalho em conjunto, a escolha do comportamento ambientalmente correto é um compromisso ético para com o outro. Em um tempo de urgências ambientais, é preciso RESGATAR o prazer do contato com a natureza, tendo o cuidado de não disseminar a ideia de uma realidade difícil demais para ser vencida. É preciso ensinar a amar e respeitar a natureza com encanto, curiosidade e esperança.

Neste resgate, pode ser incluída a importância da manutenção de áreas naturais como espaços não formais de ensino e de contribuição para a saúde mental. Em uma sociedade em que a maioria da população vive em cidades com pouco ou nenhum contato com a natureza, o contato propiciado por parques e unidades de conservação, desperta uma conexão afetiva com o meio, o que é essencial para a reconexão do indivíduo e da sociedade com o meio natural. 
Espera-se que as atitudes pós pandemia e o trabalho dos educadores ambientais realmente propiciem o desenvolvimento de cidadãos mais responsáveis com o outro, com um olhar mais sensível para a inter-relação entre pares e com a natureza. Esta pode ser uma oportunidade de repensar o modo de consumo individual e a relação com o mundo, que vem tornando os seres humanos excessivamente superficiais.

Que, na educação pós-pandemia, possamos educar com o que Edgar Morin chama de "A ética do gênero humano" cuja concepção complexa comporta a tríade indivíduo/sociedade/espécie como inseparáveis e coprodutores um do outro (MORIN, 2017).

\section{Conclusões}

O momento atual deve ser utilizado como subsídio para construção de um amanhã sustentável. Mudanças de comportamentos relacionados à saúde e higiene precisam necessariamente ser incorporados nas ações de cada um e de todos. Ações para os lares, comércios, escolas, igrejas, parques, cinemas, museus etc. Atitudes que não se resumem a mudanças temporárias, mas sim princípios a serem adotados para a posteridade.

Os comportamentos consumistas que levam o ser humano a se tornar aquilo que consome, precisam ser substituídos por uma ótica de aproveitamento, de sustentabilidade, de conexão e de harmonia com o ambiente, que leve a todos ao uso sustentado dos recursos.

Os diferentes ERRES deixam claro que é preciso REINVENTAR formas de encarar 0 mundo, as pessoas e as situações. $E$ que neste viés, seja possível REINTEGRAR o ser humano ao meio ambiente como parte de uma relação mutualista e não exploratória ou comensal. E assim, será possível RESSIGNIFICAR sua própria existência no planeta.

\section{Referências}

BRASIL. Comissão de Políticas de Desenvolvimento Sustentável e da Agenda 21 Nacional. Agenda 21 Brasileira: bases para discussão. Brasília: Ministério do Meio Ambiente, 2000. Disponível em: < https://edisciplinas.usp.br/pluginfile.php/8457/mod resource/content/1/bases di scussao agenda21.pdf > Acesso em: 26 jul 2020

BRASIL. Ministério da Saúde. Secretaria de Atenção Primária à Saúde. Nota informativa número 3 , de 04 de abril de 2020. Disponível em: $<$ https://www.saude.gov.br/images/pdf/2020/April/04/1586014047102-NotaInformativa.pdf> Acesso em: 26 jul 2020 
FOSCHINI; M. MONTE, A.F.G. Físicos da UFU avaliam quais máscaras são ais eficientes contra coronavírus. Disponível em: <http://www.comunica.ufu.br/noticia/2020/05/fisicos-da-ufu-avaliam-quaismascaras-sao-mais-eficientes-contra-coronavirus $>$ Acesso em: 26 jul 2020

FERREIRA, M.E.S.; PHILIPPSEN, H.K.; ROCHA, C.A.M. Prática lúdica em Microbiologia para alunos do Ensino Fundamental. 58 Reunião Anual da Sociedade Brasileira para o Progresso da Ciência. Anais da 58 Reunião Anual da SBPC Florianópolis, 2006. Disponível em: $<$ http://www.sbpcnet.org.br/livro/58ra/SENIOR/RESUMOS/resumo 3347.html Acesso em: 26 jul 2020

FREITAS, A. R.R.; NAPIMOGA, M.; DONALISIO, M. R. Análise da gravidade da pandemia de COVID-19. Epidemiologia e Serviços de Saúde, v.29, n. 2, 2020. Disponível em: <https://www.scielo.br/pdf/ress/v29n2/2237-9622-ress-2902-e2020119.pdf >. Acesso em: 26 jul 2020

GOERGEN, P. A ética e o futuro da humanidade: considerações críticas sobre Educação Ambiental. Pesquisa em Educação Ambiental, v.9, n.1, 2014.

MULLER, A.M.; SILVEIRA, D.D.S.; NARA, E.O.B.; KIPPER, L.M.; MORAES, J.A.R. Um olhar exploratório sobre os resíduos de serviços de saúde para os cursos da área da saúde numa universidade comunitária do Sul do Brasil. Revista Eletrônica em Gestão, Educação e Tecnologia Ambiental v.17, n.17, 2013.

NESTI, M.M.M.; GOLDBAUM, M. As creches e pré-escolas e as doenças transmissíveis. Jornal de Pediatria v. 83, n. 4, 2007.

RAMOS, Y. S. et al. Vulnerabilidade no manejo dos resíduos de serviço de saúde de João Pessoa (PB, Brasil). Ciências \& Saúde Coletiva, Rio de Janeiro, v.16, n. 8, 2011.

GARCIA, L. P.; ZANETTI-RAMOS, B. G. Gerenciamento dos resíduos de serviços de saúde: uma questão de biossegurança. Cadernos de Saúde Pública, v. 20, n. 3, 2004.

INSTITUTO BRASILEIRO DE GEOGRAFIA E ESTATÍSTICA - IBGE. Pesquisa Nacional de Saneamento Básico 2008. Rio de Janeiro, 2010. Disponível em: < https://biblioteca.ibge.gov.br/visualizacao/livros/liv45351.pdf> Acesso em: 26 jul 2020

MINAYO M.C. S. Saúde e ambiente: uma relação necessária. In: Campos GWS, organizador. Tratado de Saúde Coletiva. São Paulo: Hucitec; 2007.

MORIN, E. Os sete saberes necessários à educação do futuro. 2 ed. São Paulo: Cortez. Unesco, 2000

MUHAMMAD, S.; LONG, X.; SALMAN, M. COVID-19 pandemic and environmental pollution: $A$ blessing in disguise? Science of the total Environment v. 728, 2020. 
OPAS. Organização Panamericana da Saúde. OMS afirma que COVID-19 é agora caracterizada como pandemia. Disponível em: < https://www.paho.org/bra/index.php?option=com content\&view=article\&id=612 0:oms-afirma-que-COVID-19-e-agora-caracterizada-comopandemia\&ltemid $=812>$ Acesso em: 26 jul 2020

RATTO, C.G.; HENNING, P.C.; ANDREOLA, B.A. Educação Ambiental e suas Urgências: a constituição de uma ética planetária. Educação \& Realidade, v. 42, n. 3, 2017.

SOUZA C. L. de. ANDRADE, C.S. Saúde, meio ambiente e território: uma discussão necessária na formação em saúde. Ciência \& Saúde Coletiva v.19, n.10, 2014,

SOUZA, E. S. et al. Mortalidade e riscos associados a infecção relacionada à assistência à saúde. Texto e Contexto - Enfermagem v. 24, n. 1, 2015 Disponível em: <https://doi.org/10.1590/0104-07072015002940013 Acesso em: 26 jul 2020

VENTURA et al. Desafios da pandemia de COVID-19: por uma agenda brasileira de pesquisa em saúde global e sustentabilidade. Cadernos de Saúde Pública v.36, n. 4, 2020.

ZUPELARI, M.F.Z.; WICK, M.A.L. A incerteza do futuro e a questão ambiental na contemporaneidade. Revista Subjetividades, v.15, n.1, 2015. 